\title{
La pandemia COVID-19: Priorización sanitaria en España*
}

\author{
COVID-19 pandemic: Health prioritization in Spain
}

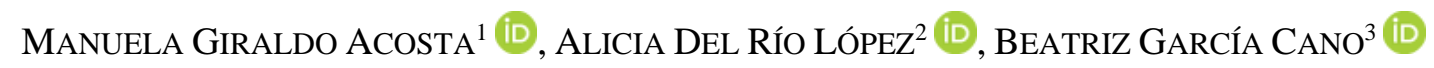

RESUMEN: La pandemia COVID-19, desarrollada durante 2020 y 2021, ha sido un acontecimiento que ha ocasionado que varios aspectos en la organización de nuestra sociedad se hayan visto afectados, provocando el desarrollo de una crisis originalmente sanitaria, que ha tenido numerosas consecuencias. Dentro del ámbito de la salud, uno de los procesos más relevantes que ha tenido que ser adaptado a esta nueva situación ha sido el triaje a causa de los escasos recursos sanitarios. Este proceso ha pasado por numerosas etapas con el fin de conseguir un protocolo estandarizado para toda España, elaborado mediante la colaboración del Ministerio de Sanidad, el Comité de Bioética de España y otras entidades. Para ello ha sido fundamental el papel de la bioética, así como el de expertos en el ámbito de la salud, científicos y juristas, ya que la visión conjunta de todos ellos ha permitido una evaluación más amplia de la situación. Al igual que en España, otros países como Francia e Italia han tenido que recurrir a comités de bioética para el manejo de la situación. La vacunación también ha necesitado del establecimiento de un triaje al no haber suficientes dosis para todos. Estos aspectos se analizan en este estudio.

Palabras clave: Bioética, COVID-19, España, ética, pandemia, triaje, utilitarismo.

ABSTRACT: The COVID-19 Pandemic, developed during 2020 and 2021, has been an event that has caused that several aspects in the organization of our society have been affected, producing the development of an originally health crisis, which has had numerous consequences. Within the health field, one of the most relevant processes that has had to be adapted to this new situation has been triage due to scarce health resources. This process has gone through numerous stages in order to achieve a standardized protocol for Spain, prepared in collaboration with the Ministry of Health, the Bioethics Committee of Spain and other entities. For this, the role of bioethics has been fundamental, as well as that of experts in the field of health, scientists and lawyers, since the joint vision of all of them has allowed a broader evaluation of the situation. As in Spain, other countries such as France and Italy have had to resort to bioethics committees to manage the situation. Vaccination has also required the establishment of a triage as there are not enough doses for everyone. These aspects are evaluated in this study.

Keywords: Bioethics, COVID-19, ethics, Spain, triage, pandemic, utilitarianism.

SUMARIO: I. INTRODUCCIÓN. II. DEFINICIÓN DE TRIAJE. 1. Aspectos bioéticos a tener en cuenta en el triaje. III. TRIAJE EN CENTROS SANITARIOS EN ESPAÑA DURANTE LA PANDEMIa COVID-19. 1. Actuaciones de entidades externas a la Administración Pública. 2. Actuación del Comité de Bioética de España. 3. Actuación del Ministerio de Sanidad de España. IV. TRIAJE EN CENTROS SANITARIOS EN OTROS PAísES DURANTE LA PANDEMIA COVID-19. 1. Proceso de triaje en Italia. 2. Proceso de triaje en Francia. V. OTROS Ámbitos del TRIAJE DURANTE LA PANDEMIA. VI. CONCLUSIÓN. VII. BiBLIOGRAFÍA.

\footnotetext{
* Fecha de recepción: 27/05/2021 - Fecha de aceptación: 09/11/2021. Cita recomendada: Giraldo Acosta, M., Del Río López, A., \& García Cano, B. (2021). La pandemia COVID-19: Priorización sanitaria en España. Bioderecho.es, (13), 1-26. https://doi.org/10.6018/bioderecho.481321

${ }^{1}$ Universidad de Murcia. Correo: manuela.giraldoa@um.es

${ }^{2}$ Universidad de Murcia. Correo: alicia.delr@um.es

${ }^{3}$ Universidad de Murcia. Correo: beatriz.ze99@gmail.com
} 


\section{INTRODUCCIÓN}

El año 2020 ha estado marcado en gran medida por la pandemia COVID-19, situación generada por la propagación mundial del virus SARS-CoV-2. Este virus ha obligado a las distintas sociedades a hacer frente a situaciones enmarcadas en un contexto de crisis global. En primer lugar, una crisis sanitaria, con millones de muertos y afectados en el mundo. Seguidamente, una crisis económica, ya que las decisiones tomadas por los distintos gobiernos han supuesto restricciones en varios sectores de la economía (turismo, hostelería, hoteles, ocio, etc.) y, finalmente, una crisis social, afectando a millones de personas en distintos países del mundo ${ }^{1}$. Todas las restricciones y cambios en la vida de las personas sobrevenidos después del inicio de la pandemia han estado condicionadas por esta crisis global, siendo necesario el desarrollo de numerosos y nuevos protocolos de actuación en diversos aspectos de la sociedad tanto española como mundial.

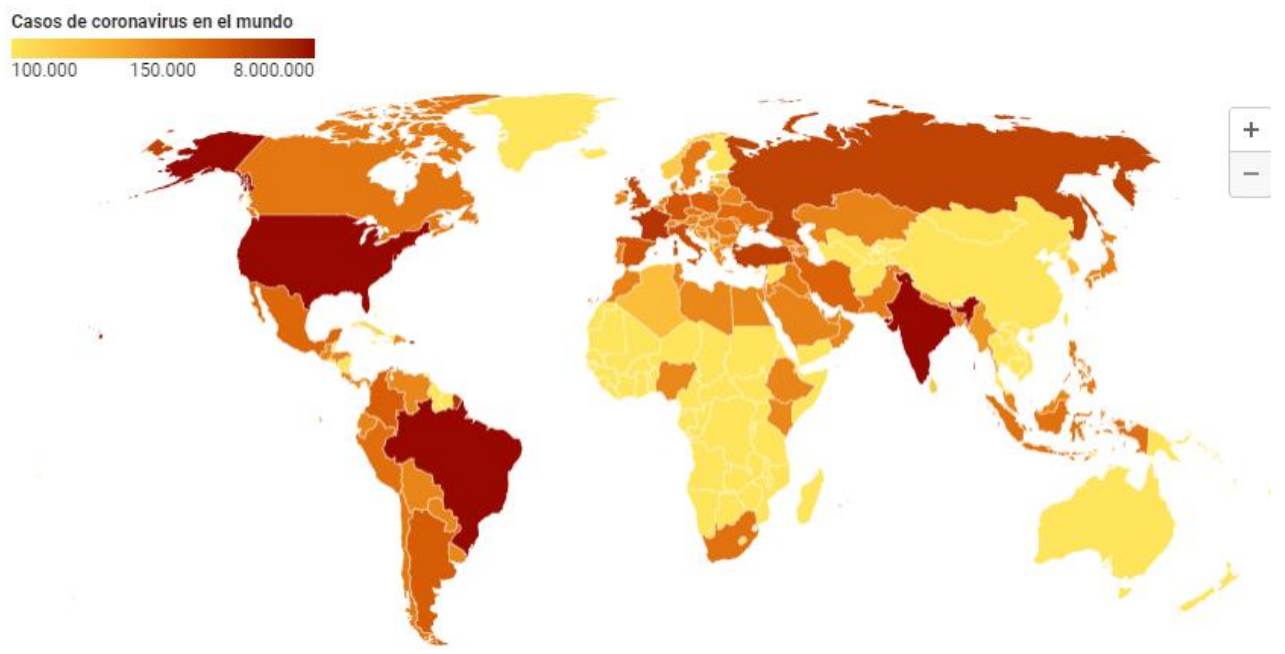

Figura 1: Casos de coronavirus en el mundo. Imagen tomada de la página https://www.rtve.es/noticias/20210522/mapa-mundial-del-coronavirus/1998143.shtml\#situacion-mundo ${ }^{1}$

Si bien actualmente se trata de una crisis sanitaria, económica y social, al inicio se planteaba como un problema únicamente sanitario, por lo que las primeras medidas tomadas por parte de diversas entidades competentes fueron en este ámbito. El análisis de las medidas sanitarias tomadas durante la pandemia COVID-19 y los aspectos bioéticos de estas han sido y siguen siendo un punto crítico en la gestión de la situación. Uno de los aspectos sanitarios más destacado durante esta pandemia ha sido el proceso de triaje en los centros sanitarios de los distintos países. La realización de una selección de los pacientes para el correcto uso de los recursos disponibles es un tema que pone en evidencia la capacidad que tienen los países y, en definitiva, sus instituciones para la aplicación de unos criterios que sean justos y éticos para todas las personas. El establecimiento de protocolos para el triaje en centros sanitarios españoles ha pasado por distintas etapas a lo largo del desarrollo de esta pandemia y, estas etapas y sus puntos más relevantes serán objeto de análisis en este estudio. Además, se realizará una comparación entre la evolución del proceso de triaje entre España y otros países en los que la situación difiera

\footnotetext{
1 DATOS RTVE, "Mapa del coronavirus en el mundo: casos, muertes y los últimos datos de su evolución", DatosRTVE, 2021, disponible en https://www.rtve.es/noticias/20210522/mapa-mundial-delcoronavirus/1998143.shtml\#situacion-mundo Consultado 22/05/2021
} 
en cierta medida de la española. Hay varios elementos a tener en cuenta, ya que los gobiernos, los recursos y la aplicación de la ética no son iguales en los distintos estados.

Con la finalidad de que las decisiones tomadas con respecto al triaje respeten la dignidad de las personas es necesario realizar un amplio análisis de los conceptos éticos que se aplican en el ámbito sanitario, permitiendo una mejor selección y aplicación de estas medidas. Para ello, es necesario el trabajo de equipos multidisciplinares en los que convergen diversos puntos desde los que se puede abordar esta situación y que suponen un enriquecimiento en el conocimiento que se aplica para la toma de decisiones. Además, el trabajo conjunto de varios profesionales supone también un apoyo moral entre ellos ante la responsabilidad de toma de decisiones que tienen repercusión directa en las personas y en su salud, tanto física como mental.

La pandemia COVID-19 ha supuesto una situación sin precedentes a nivel mundial y ha puesto en evidencia numerosos vacíos en distintos países, como son la falta de recursos sanitarios, la falta de personal sanitario, la inversión en investigación, la falta de protocolos unificados en el proceso de triaje, entre otros. En este estudio se analiza el proceso de triaje en centros sanitarios durante la pandemia COVID-19 en España. Sin embargo, todos estos aspectos deben ser analizados más profundamente con el fin de adquirir herramientas para situaciones posteriores.

\section{DEFINICIÓN DE TRIAJE}

Para analizar en profundidad el significado de la palabra "triaje" es necesario conocer el origen de esta y el uso que se hacía de ella inicialmente. De este modo, el término triaje proviene de la palabra francesa "trier" que significa escoger, separar o clasificar. En el ámbito sanitario se pueden distinguir dos grandes "tipos" de triaje: por un lado, el triaje que se realiza diariamente en centros sanitarios, que consiste en el manejo adecuado de los pacientes atendiendo a unos criterios, y el triaje en situaciones extremas de índole sanitaria ${ }^{2}$. Este triaje encuentra su fundamento en el siguiente enunciado: "el mayor beneficio para el mayor número de personas". Para ello, es de suma importancia realizar una selección y clasificación de pacientes, con el fin de atender al máximo número de personas con los recursos de los que se dispone. En las situaciones extremas, el triaje se basa en tres criterios generales: la supervivencia o prioridad asistencial, la calidad de vida y los recursos necesarios para garantizar la supervivencia ${ }^{3}$.

Con respecto al primer criterio, se podría ejemplificar de la siguiente manera: ante un paciente con una situación de alta gravedad que tiene bajas probabilidades de sobrevivir y otro con una situación de menor gravedad, pero con más probabilidad de sobrevivir, este último tendría una mayor prioridad asistencial ${ }^{3}$. Este hecho puede relacionarse con el principio de beneficencia de la ética médica que busca lo mejor para el paciente. Sin embargo, este no es el único principio que se aplica cuando se lleva a cabo el proceso de triaje, sino que se aplican varios principios con el fin de maximizar los beneficios que se pueden obtener con los recursos disponibles. Con respecto al segundo criterio, la calidad de vida, este hace referencia a, una vez aplicado el criterio de supervivencia, de qué manera se pueden utilizar los recursos disponibles para que el sujeto en cuestión tenga unas condiciones de vida dignas. Por último, el criterio de supervivencia hace referencia a la aplicación de los recursos disponibles con el fin de garantizar que la vida de las personas continúe. Resumidamente, los tres criterios conllevan la correcta gestión de los recursos y la maximización de los beneficios que esto pueda tener en la vida de las personas.

\footnotetext{
2 CHRISTIAN, M. D., "Triage”, Critical care clinics, Vol. 35, Núm. 4, 2019, pp. 575-589. https://doi.org/10.1016/j.ccc.2019.06.009

${ }^{3}$ LISA ROSENBAUM, M.D., "Facing Covid-19 in Italy - Ethics, Logistics, and Therapeutics on the Epidemic's Front Line", The new England journal of medicine, 14 de mayo de 2020, disponible en https://www.nejm.org/doi/full/10.1056/nejmp2005492
} 
Las situaciones no habituales en las que se puede necesitar un proceso de triaje diferente al habitual en centros hospitalarios pueden ser desastres naturales como terremotos, catástrofes donde hay una situación de grave peligro para la sociedad, guerras, epidemias y pandemias, entre otras. De este modo, el triaje durante situaciones extremas se puede clasificar en primario, secundario y terciario ${ }^{4}$.

En situaciones de desastres suelen ser muchos los afectados, lo que supone la aplicación de un triaje primario: es el que tiene lugar en la propia zona del desastre y engloba los procesos de evacuación, transporte en ambulancia, tratamiento en el propio lugar si fuese necesario. Se aplican unos criterios para priorizar el tratamiento de alguien, su evacuación o transporte. El triaje secundario es el que, una vez en el centro sanitario, consiste en realizar una selección de las personas que tiene prioridad para el uso de los recursos allí disponibles. Por último, el triaje terciario se realiza entre las personas que son atendidas en los centros sanitarios y que consiste en la elección de quién es prioritario para el ingreso en la Unidad de Cuidados Intensivos (UCI). Los tipos de triaje que se dan en situaciones extremas se recogen en la Tabla 1.

Tabla 1. Tipos de triaje en situaciones extrema ${ }^{5}$.

\begin{tabular}{|l|l|l|}
\hline Clasificación & Dónde se realiza el triaje & Descripción \\
\hline Triaje primario & Lugar del desastre & $\begin{array}{l}\text { Consiste en el triaje que se realiza } \\
\text { para la evacuación, transporte en } \\
\text { ambulancia, tratamiento en el propio } \\
\text { lugar del suceso. }\end{array}$ \\
\hline Triaje secundario & Triaje en el centro sanitario & $\begin{array}{l}\text { Consiste en el triaje para el acceso o } \\
\text { para el uso de los recursos } \\
\text { disponibles en el centro sanitario. }\end{array}$ \\
\hline Triaje terciario & Triaje en el centro sanitario & $\begin{array}{l}\text { Consiste en el triaje para el ingreso } \\
\text { en la Unidad de Cuidados Intensivos } \\
\text { (UCI) }\end{array}$ \\
\hline
\end{tabular}

El rendimiento de los recursos de los que se dispone está definido por la cantidad y calidad de estos, pero también por el factor tiempo, ya que pueden darse ocasiones donde los recursos no van a ser suficientes para la duración de un determinado evento ${ }^{6}$. Por ejemplo, en el caso de la pandemia COVID-19, han sido varios los países en los que la necesidad de atención ha sido muy superior a la cantidad de los recursos sanitarios disponibles. Por tanto, es fundamental que se establezcan planes de triaje para que el rendimiento del uso de los recursos sea el máximo y evitar en la medida de lo posible el mal uso de esto.

\section{Aspectos bioéticos a tener en cuenta en el triaje}

En el proceso de triaje sanitario, es decir, en situaciones en las que hay que establecer criterios para la selección entre pacientes, es fundamental regirse por la ética y por el precepto de

\footnotetext{
${ }^{4}$ CHRISTIAN, M. D., "Triage”..., cit.

${ }^{5}$ HERREROS, B., GELLA, P., REAL DE ASUA, D., "Triage during the COVID-19 epidemic in Spain: better and worse ethical arguments", Journal of Medical Ethics, Vol. 46, 2020, pp. 455-458. http://dx.doi.org/10.1136/medethics$\underline{2020-106352}$

${ }^{6}$ CHRISTIAN, M. D., “Triage”..., cit.
} 
respeto de la vida, de la dignidad e integridad humana. Según Biddison $(2014)^{7}$, los principios éticos a tener en cuenta en situaciones de triaje en desastres o pandemias son aquellos que respeten y honren la autonomía, la justicia y la beneficencia y no maleficencia, y los que cumplan los requisitos para administrar los recursos y promover la equidad, transparencia, proporcionalidad y responsabilidad.

El principio ético de autonomía en el ámbito sanitario deja de lado el paternalismo médico, entendido como la manera de proceder del médico o sanitario en la que sus conocimientos y sus decisiones están por encima de las consideraciones del paciente. Esta forma de proceder se respalda en la creencia de que el médico/sanitario "sabe lo que es mejor para el paciente". Así pues, el principio de autonomía defiende que es el propio paciente el que tiene que tomar la decisión final con respecto a una intervención sobre su persona en el ámbito sanitario. La elección del paciente debe ser libre y consciente, por lo que es necesario que tenga en su poder la información necesaria para ello. El principio ético de justicia defiende el trato equitativo de las personas, no pudiendo este estar condicionado por el sexo, nacionalidad, religión, orientación sexual o cualquier otro aspecto que defina a una persona. El principio ético de beneficencia obliga a buscar siempre un beneficio para las personas. Sin embargo, no hay que confundir el buscar el beneficio con el paternalismo médico: puede ocurrir que algo que se considere beneficioso para un paciente sea rechazado por el propio paciente. En este caso, es el principio de autonomía el que prevalece. Por el contrario, el principio ético de no maleficencia es de obligado cumplimiento sea cual sea la situación, ya que nunca será éticamente correcto hacerle el mal a una persona, pero no siempre será correcto hacer el bien (Principio de autonomía). El principio de equidad va de la mano con el principio ético de justicia. En el ámbito sanitario supone que, ante una situación equiparable, el acceso a los recursos, la atención y la calidad debe ser igual para todos los pacientes. De este mismo modo, el principio de proporcionalidad está íntimamente relacionado con el principio de equidad y de justicia, ya que obliga a los sanitarios a realizar una valoración de la situación para aplicar la justicia, la equidad y la proporcionalidad en sus actos. El principio de transparencia va de la mano del principio ético de autonomía, ya que para que una persona pueda tomar decisiones de forma autónoma es necesario que tenga a su disposición toda la información necesaria, es decir, que el personal sanitario actúe de forma transparente con el paciente con el fin de garantizar la autonomía de este. El principio de responsabilidad está estrechamente relacionado con las normas deontológicas de la profesión de los sanitarios, significando esto que el ejercicio de la profesión conlleva la asunción de determinadas responsabilidades en la toma de decisiones ${ }^{8}$. De este modo, estos conceptos se resumen en la Tabla 2.

\footnotetext{
${ }^{7}$ DAUGHERTY BIDDISON, L., BERKOWITZ, K. A., COURTNEY, B., DICHTER, J. R., CHRISTIAN, M. D., POWELL, T., "Care of the Critically Ill and Injured During Pandemics and Disasters: CHEST Consensus Statement", CHEST journal, Vol. 146, Núm. 4, 2014, pp. 145-155. https://doi.org/10.1378/chest.14-0742

${ }^{8}$ BEAUCHAMP, T.L., "Métodos y principios en ética biomédica", Revista de Ética Médica, Vol. 29, 2003; pp. 269274. https://jme.bmj.com/content/29/5/269; TAYLOR, R.M., "Ethical principles and concepts in medicine", Handb Clin Neurol., Vol 118, 2013, pp. 1-9. https://doi.org/10.1016/B978-0-444-53501-6.00001-9; GILLON, R. "Ética médica: cuatro principios más atención al alcance", $B M J$, Vol. 309, 1994, p. 184, disponible en https://www.bmj.com/content/309/6948/184.full
} 
Tabla 2. Principios éticos en el triaje?.

\begin{tabular}{|c|c|}
\hline Principios éticos en triaje & Definición \\
\hline Autonomía & $\begin{array}{l}\text { Principio que obliga a respetar las decisiones de las personas autónomas, } \\
\text { siendo estas las que tienen capacidad de decisión libre y consciente. }\end{array}$ \\
\hline Justicia & $\begin{array}{l}\text { Principio que obliga a una distribución equitativa entre beneficios y riesgos } \\
\text { para todas las personas. Según Guillon (1994) existen tres tipos de justicia en } \\
\text { el ámbito sanitario: Justicia distributiva (distribución justa de recursos } \\
\text { escasos), Justicia basada en los derechos (respeto de los derechos de las } \\
\text { personas) y Justicia legal (respeto de las leyes moralmente aceptables). }\end{array}$ \\
\hline Beneficencia/No maleficencia & $\begin{array}{l}\text { Principios que obligan a actuar en beneficio de los demás, a minimizar la } \\
\text { relación riesgos/beneficios, es decir, que los riesgos sean los mínimos y los } \\
\text { beneficios los máximos, y a no causar daño a los demás. }\end{array}$ \\
\hline Equidad & $\begin{array}{l}\text { Se define como el principio que en el ámbito sanitario supone igual acceso a la } \\
\text { atención disponible, igual uso e igual calidad de atención para todos, ante una } \\
\text { situación equiparable. }\end{array}$ \\
\hline Transparencia & $\begin{array}{l}\text { Principio que supone la obligación de actuar de manera en la que no se oculte } \\
\text { ni se tergiverse la información o la situación. Actuar de manera transparente } \\
\text { conlleva implícitamente el respeto a la autonomía de las personas. }\end{array}$ \\
\hline Proporcionalidad & $\begin{array}{l}\text { El principio de proporcionalidad en el ámbito sanitario repercute directamente } \\
\text { con la actuación de los sanitarios: ellos deben actuar realizando una valoración } \\
\text { de la situación, de los recursos de los que se disponen y de las consecuencias } \\
\text { de dicha actuación, para que las medidas tomadas tengan una relación de } \\
\text { proporcionalidad con la situación global, respetando en todo momento los } \\
\text { principios de justicia y de beneficencia. }\end{array}$ \\
\hline Responsabilidad & $\begin{array}{l}\text { Se trata de un principio directamente relacionado con la aplicación de los } \\
\text { principios deontológicos de la profesión. En este caso, el personal sanitario } \\
\text { debe responsabilizarse de sus actuaciones. }\end{array}$ \\
\hline
\end{tabular}

${ }^{9}$ GILLON, R. "Ética médica: cuatro...”, cit.; BRAVEMAN, P., "Disparidades en salud y equidad en salud: conceptos y medición.", Annual Review of Public Health, Vol. 27, Núm. 1, 2006, pp. 167-194. https://doi.org/10.1146/annurev.publhealth.27.021405.102103; ROBERTS, M. J., REICH, M. R., "Ethical analysis in public health", The Lancet, Vol. 359, Núm. 9311, 2002, pp. 1055-1059. https://doi.org/10.1016/S0140-6736(02)08097$\underline{2}$ 


\section{TRIAJE EN CENTROS SANITARIOS EN ESPAÑA DURANTE LA PANDEMIA COVID-19}

El proceso de triaje en los Centros Sanitarios Españoles (CSE) durante la pandemia COVID-19 ha pasado por varias fases. En un primer momento, el proceso de triaje no se encontraba unificado, por lo que cada CSE tenía unos criterios propios de triaje, establecidos por el personal sanitario de cada centro. Esta situación supuso desigualdades entre personas y, por lo tanto, no era una situación que cumpliese con los principios éticos que deben respetarse en situaciones extremas en las que sea necesaria la realización de un triaje. Según Federico de Montalvo y Vicente Bellver (2020): "La calamidad que padecemos nos ha alcanzado desprovistos de recursos para afrontarla, pero no solo de recursos sanitarios, sino también bioéticos. Es cierto que existe una literatura específica sobre la asignación equitativa de recursos durante los desastres naturales, y, en general, sobre los problemas bioéticos suscitados con ocasión de las pandemias. Pero apenas tenía cabida en los programas de post-grado en Bioética, mucho menos en la formación de grado de las profesiones sanitarias"10.

Ante esta situación, varias entidades independientes de la administración pública, como la Sociedad Española de Medicina Intensiva, Crítica y Unidades Coronarias (SEMICYUC) o la Comisión Central de Deontología del Consejo General de Colegios Oficiales de Médicos (CGCOM), realizaron diversas intervenciones que supusieron la redacción de varios documentos oficiales. En estos documentos se realizaba una revisión de la situación y se proponían criterios de triaje para los CSE. Esto supuso la intervención del Comité de Bioética de España (CBE) mediante la redacción de un informe oficial en el que se analizan los documentos redactados por estas entidades y en el que se proponen varios puntos en relación con el proceso de triaje durante la pandemia. Finalmente, es el Gobierno de España a través del Ministerio de Sanidad el que, tras el análisis de los puntos más importantes y controvertidos de todas estas publicaciones, redacta un informe oficial en el que se establecen los criterios de priorización unificados que debían obedecer todos los Centros Sanitarios Españoles.

Todos los sucesos, intervenciones y documentos realizados a partir de esta premisa se desarrollan en los siguientes subapartados y se resumen en la Figura 2.

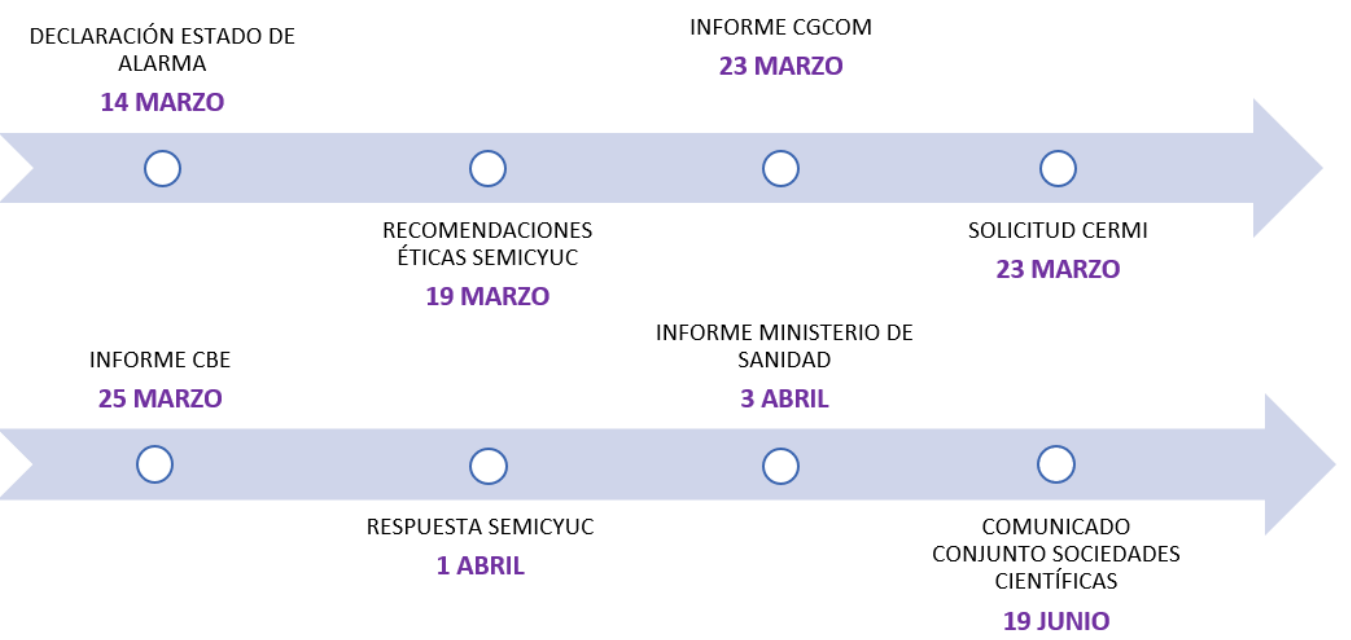

Figura 2. Eje temporal de las intervenciones de las distintas organizaciones sobre los criterios adoptados en España en el año 2020.Imagen propia.

\footnotetext{
${ }^{10}$ MONTALVO JÄÄSKELÄINEN, F., BELLVER CAPELLA, V., "Una crisis bioética dentro de la crisis sanitaria provocada por la covid-19: una reflexión sobre la priorización de pacientes en tiempos de pandemia.", Derecho y Salud, Vol. 30, 2020, disponible en https://www.ajs.es/sites/default/files/2020-07/vol30_Extra_02_05_Estudio.pdf
} 


\section{Actuaciones de entidades externas a la Administración Pública}

La formación recibida por los profesionales sanitarios a lo largo de sus estudios de Grado es muy completa en cuanto a materias biológicas y sanitarias. Sin embargo, en el ámbito de la bioética y, más concretamente, en el ámbito de desastres que conllevan una priorización entre un gran número de personas, la formación es más escasa. Es por ello por lo que su perspectiva ética puede llegar a resultar insuficiente en contextos de emergencias sanitarias en las que es necesario integrar los deberes de cuidado de los pacientes individuales con los deberes hacia un colectivo más amplio ${ }^{11}$.

Teniendo en cuenta lo anterior, resulta sencillo llegar a la conclusión de que la toma de decisiones no debe llevarse a cabo únicamente por el personal sanitario. La siguiente pregunta que cabe plantearse es a quién compete la fijación de unos criterios de priorización en el contexto de esta pandemia, ¿a las autoridades sanitarias, a las sociedades científicas, al Gobierno de España?

A principios de marzo, la ciencia se adelantó a la política en la propuesta de soluciones para uno de los principales retos de esta pandemia: la necesaria priorización de unos recursos sanitarios escasos para el volumen de la demanda asistencial. Esta propuesta se vio reflejada en varios documentos publicados por diversas asociaciones como la SEMICYUC bajo el título Recomendaciones éticas para la toma de decisiones en la situación excepcional de crisis por pandemia covid-19 en las unidades de cuidados intensivos ${ }^{12}$ o la CGCOM mediante el Informe de la Comisión Central de Deontología en relación a la priorización de las decisiones sobre los enfermos en estado crítico en una catástrofe sanitaria ${ }^{13}$.

Estos escritos fueron publicados con el objetivo de servir de ayuda a los clínicos en la toma responsable de decisiones sobre casos individuales, que pueden no solo ser técnica y éticamente difíciles, sino también emocionalmente gravosas ${ }^{14}$. Sin embargo, el primer documento confeccionado por el Grupo de Trabajo de Bioética de la SEMICYUC fue sin duda el más controvertido por las implicaciones éticas que podría tener dicho informe para las personas mayores o discapacitados. Algunos de los conceptos más controvertidos son los que hacen referencia a cuestiones tales como "supervivencia libre de discapacidad por encima de la supervivencia aislada" o la que recomienda que "Cualquier paciente con deterioro cognitivo, por demencia u otras enfermedades degenerativas, no serían subsidiarios de ventilación mecánica invasiva". Este informe no solo generó debates éticos, sino también políticos-administrativos, ya que una sociedad científica puede proporcionar conocimientos a la sociedad y a la propia Administración Pública, pero nunca puede establecer la priorización ante una limitación de recursos ${ }^{15}$.

\footnotetext{
${ }^{11}$ Ibidem.

${ }^{12}$ GRUPO DE TRABAJO DE BIOÉTICA DE LA SEMICYUC, "Recomendaciones éticas para la toma de decisiones en la situación excepcional de crisis por pandemia covid-19 en las unidades de cuidados intensivos", semicyuc.org, 19 de marzo de 2020, disponible en https://semicyuc.org/wp-content/uploads/2020/03/\%C3\%89tica_SEMICYUCCOVID-19.pdf

13 COMISIÓN CENTRAL DE DEONTOLOGÍA DEL CONSEJO GENERAL DE COLEGIOS OFICIALES DE MÉDICOS, "Informe de la Comisión Central de Deontología en relación a la priorización de las decisiones sobre los enfermos en estado crítico en una catástrofe sanitaria.", cgcom.es, 23 de marzo de 2020, disponible en https://www.cgcom.es/informe-de-la-comisi\%C3\%B3n-central-de-deontolog\%C3\%ADa-en-relaci\%C3\%B3n-lapriorizaci\%C3\%B3n-de-las-decisiones-sobre

${ }^{14}$ MONTALVO JÄÄSKELÄINEN, F., BELLVER CAPELLA, V., “Una crisis bioética...”, cit.

15 REAL DE ASÚA, D., GALVÁN, J. M., IGLESIAS, J., FERNÁNDEZ, J., (2020). "Criterios de triaje para reanimación cardiopulmonar y soporte vital avanzado durante la epidemia COVID-19", Medicina Clínica, Vol. 155, Núm. 5, 2020, pp. 215-219. https://doi.org/10.1016/j.medcli.2020.04.009
} 
Esto hizo despertar la atención de diferentes entidades que salieron en defensa de los derechos de las personas con discapacidad, entre otros. Así lo demuestra el Defensor del pueblo en su resolución de Actuaciones frente a la pandemia de covid-19 mediante el siguiente enunciado: "Una denegación a grupos de personas, por edad o por discapacidad, no es admisible. Cada persona tiene unas características, un estado de salud, unas condiciones clínicas que los médicos tienen que valorar, y hay que dedicarle toda la atención que esa concreta persona precisa, con los recursos y medios materiales que haya disponible"16.

A este comisionado se sumó la petición de la Dirección General de Políticas de Discapacidad del Ministerio de Derechos Sociales y Agenda 2030, que instó al gobierno a garantizar durante la pandemia una atención sanitaria equitativa y sin discriminaciones, incitándole a realizar una estrecha vigilancia a las recomendaciones emitidas por entidades como las sociedades científicas sobre el uso de los recursos en la situación "excepcional" y sobre los efectos que puede tener sobre las personas con discapacidad, que, según esta: "[...] no solo carecen de valor oficial sino que por su contenido contrario a nuestro ordenamiento jurídico, constituyen una praxis perturbadora capaz de comprometer el bien supremo a la vida de las personas con discapacidad" ${ }^{17}$.Tras recibir esta solicitud, el Comité de Bioética se vio incentivado a redactar el informe que tenía pendiente de publicar sobre los aspectos bioéticos de la priorización de recursos, desarrollado en el siguiente apartado.

Ante todos estos sucesos generados por el primer documento de recomendaciones previas de la SEMICYUC, esta misma entidad respondió finalmente el día 1 de abril de 2020 con un comunicado oficial aclarando, por un lado, no haber puesto nunca en entredicho la potestad de la administración pública como única facultada constitucionalmente para limitar y suspender derechos $\mathrm{y}$, por otro lado, la falta de concreción del término "utilidad social" que aparece en su primer informe. Además, la SEMICYUC justifica su temprana intervención mediante sus primeras recomendaciones ante el silencio de la administración pública.

Como el propio Informe del Comité de Bioética de España señala, ya se estaban redactando y aplicando de manera independiente protocolos de triaje en algunos centros sanitarios. Como ya hemos señalado con anterioridad, la SEMICYUC considera que es necesario que dichos criterios sean uniformes y que sea la autoridad pública quien lidere y coordine su elaboración, si bien, hasta la fecha no ha sido así ${ }^{18}$.

Añadido a esto, el día 19 de junio de 2020, varias comunidades médico-científicas se ponen de acuerdo para la emisión de un comunicado conjunto en respuesta a las últimas noticias recogidas en los medios de comunicación y redes sociales que hablaban de una mala actuación por parte de los sanitarios frente al proceso priorización de recursos. En este comunicado, todas estas asociaciones manifiestan su apoyo a los profesionales sanitarios, asegurando que en todo momento han sido fieles a las normas éticas y deontológicas de la profesión, tomado decisiones

\footnotetext{
16 DEFENSOR DEL PUEBLO, “Actuaciones ante la pandemia de covid-19”, Pág. 88, defensordelpueblo.es, 2020, disponible en https://www.defensordelpueblo.es/wp-content/uploads/2020/12/Documento_COVID-19.pdf

${ }^{17}$ VALLE, R., "La protección de los derechos de las personas con discapacidad en situaciones de crisis: la emergencia sanitaria del COVID-19 en España", Revista Española de Discapacidad, Vol. 8, Núm. 2, 2020, pp. 85-106. https://doi.org/10.5569/2340-5104.08.02.04

${ }^{18}$ GRUPO DE TRABAJO DE BIOÉTICA DE LA SEMICYUC, "Comunicado de la junta directiva de la Sociedad Española de Medicina Intensiva, Crítica y Unidades Coronarias (SEMICYUC) sobre el informe del Comité de bioética de España sobre los aspectos bioéticos de la priorización de recursos sanitarios en el contexto de la crisis del coronavirus.", semicyuc.org, 1 de abril de 2020, disponible en https://semicyuc.org/wpcontent/uploads/2020/04/Comunicado-SEMICYUC-Bioe\%CC\%81tica.pdf
} 
clínicas de elevadísima complejidad, y siempre atendiendo a criterios médicos y a las necesidades clínicas concretas de cada paciente ${ }^{19}$.

\section{Actuación del Comité de Bioética de España}

El Comité de Bioética de España (CBE) es el órgano del Estado español que tiene como finalidad la emisión de informes, propuestas y recomendaciones para los poderes públicos de ámbito estatal y autonómico sobre cuestiones con implicaciones éticas y sociales de la Biomedicina y Ciencias de la Salud. Además, tiene funciones como el establecimiento de los principios generales para la elaboración de códigos de buenas prácticas de investigación científica y la representación de España en los foros y organismos internacionales implicados en la bioética. Fue creado por la Ley 14/2007, de 3 de julio, de Investigación Biomédica (BOE 4 de julio). Se entiende como un órgano colegiado, independiente y de carácter consultivo ${ }^{20}$.

La actuación de este órgano en el contexto de la pandemia por COVID-19 comienza a partir de la observación de la disparidad de criterios de triaje adoptados en los centros sanitarios de manera individualizada y no unificada, lo que suponía un trato no igualitario entre los pacientes por el simple hecho de estar adscritos a un determinado centro sanitario. Esto supuso la intervención del Comité de Bioética de España mediante la redacción de una carta dirigida al Ministerio de Sanidad Español el día 04 de marzo de 2020. En esta carta se puso de manifiesto la preocupación del comité frente a la necesidad de elaborar unos criterios uniformes sobre la priorización de pacientes, a la vista de que, en ese momento, los protocolos se estaban aprobando de manera independiente por cada centro sanitario, sin atender a unos criterios comunes ni garantizar la participación de expertos en Bioética. El ofrecimiento del Comité a participar en la elaboración de estos criterios fue bien acogido por parte del Ministerio de Sanidad de España, y fue respondido con la petición de elaborar un informe por su parte, en el que se recogieran todos estos aspectos bioéticos implicados en la toma de decisiones. Es por ello, por lo que se observó la necesidad de que los Comités de Ética Asistencial, presentes en la mayoría de los centros hospitalarios, tuvieran un importante papel en dicha labor de manejo del proceso de triaje.

Así, el 25 de marzo de 2020, el Comité de Bioética publica un informe que trata una serie de puntos que se irán desarrollando a continuación. Cabe destacar que la intervención del Comité de Bioética se vio influenciada por el hecho de que varios de sus componentes sufrieron la enfermedad COVID-19 y, por lo tanto, esta intervención tuvo que retrasarse en el tiempo. De esta forma lo relatan al inicio del propio informe emitido el 25 de marzo de 2020 por este órgano: "La situación en la que involuntariamente nos hemos visto inmersos, nos ha impedido ponernos a trabajar con anterioridad en las cuestiones bioéticas de esta crisis del coronavirus como hubiera sido nuestro deseo" 21 .

Para empezar el informe, los componentes del Comité tratan la importancia de prevenir la extensión de una mentalidad utilitarista, haciendo referencia a las recomendaciones desarrolladas por la SEMICYUC en su informe por el uso de algunos conceptos que generan cierta controversia como el de "utilidad social". Esta mentalidad se fundamenta en la

\footnotetext{
19 SOCIEDADES MÉDICO-CIENTÍFICAS, "Comunicado conjunto sobre asistencia a pacientes COVID-19", semicyuc.org, 19 de junio de 2020, disponible enhttps://semicyuc.org/wp-content/uploads/2020/06/Comunicadoconjunto-10-SS.CC.-19-de-junio-de-2020.pdf

${ }^{20}$ COMITÉ DE BIOÉTICA DE ESPAÑA, Página web oficial disponible en http://www.comitedebioetica.es/

${ }^{21}$ COMITÉ DE BIOÉTICA DE ESPAÑA, "Informe del Comité de bioética de España sobre los aspectos bioéticos de la priorización de recursos sanitarios en el contexto de la crisis del coronavirus", comitedebioetica.es, 25 de marzo de 2020, Pág. 2, disponible en http://assets.comitedebioetica.es/files/documentacion/Informe\%20CBE\%20Priorizacion\%20de\%20recursos\%20sanitarios-coronavirus\%20CBE.pdf
} 
"maximización de la utilidad", lo que quiere decir que la aplicación de este modelo ético supondría el maximizar lo que es beneficioso para la mayoría. Esto deriva en que ciertas minorías se verían sometidas a la marginación y a un trato injusto ${ }^{22}$.

Haciendo referencia al documento confeccionado por el Grupo de Trabajo de Bioética de la Sociedad Española de Medicina Intensiva, Crítica y Unidades Coronarias (SEMICYUC) bajo el título de Recomendaciones éticas para la toma de decisiones en la situación excepcional de crisis por pandemia covid-19 en las unidades de cuidados intensivos, el Comité de Bioética de España manifiesta en este informe su desacuerdo con algunos de los conceptos que se emplean en este, en referencia a personas con distintas discapacidades, ya que no son compatibles con la Convención Internacional sobre los Derechos de las Personas con Discapacidad, tratado firmado y ratificado por España ${ }^{23}$.

En el informe también se hace referencia a que la crisis causada por este virus es en esencia una crisis de salud pública. De este modo, remarcan que el estado y los ciudadanos y ciudadanas deben cooperar para hacer frente a esta crisis de salud pública, así como reforzar y dotar de instrumentos a la sanidad tanto pública como privada, permitiendo así la reducción del impacto que esta tenga y sus consecuencias (crisis económica, crisis social, crisis educativa). Además, se remarca el papel que jugamos los ciudadanos y ciudadanas, así como los medios de comunicación y redes sociales, a la hora del cumplimiento de uno de los principios bioéticos más antiguos: "Primero no hacer daño" (Primum non nocere). Hacen énfasis en la prudencia a la hora de la difusión de información y ser conscientes del impacto que esto puede tener en la sociedad para así evitar hacer daño a los demás.

En otro de los puntos que se desarrolla en el informe del Comité se describe la preocupación de este por la aplicación del criterio de la edad para el proceso del triaje para la asistencia. Es necesario valorar las circunstancias concretas de cada paciente, sin excluir a nadie a priori. La única posible excepción de discriminación positiva por la edad son los menores de edad (niños y adolescentes), ya que el principio que se debe tener en cuenta en estos casos es el del interés superior del menor ${ }^{24}$.

Uno de los puntos más relevantes de este informe es el punto 9 y los subpuntos que lo componen. En él se desarrollan los elementos a tener en cuenta para la creación de unos criterios unificados para el proceso de triaje en los centros sanitarios españoles, con el fin de evitar grandes inequidades asistenciales. Para ello, en primer lugar, instan al Gobierno a crear con la mayor brevedad posible un comité en el que se integren expertos del ámbito científico, clínico y bioético con la finalidad de poner en común distintas perspectivas. Por otro lado, remarcan la importancia

22 SAVULESCU, J., PERSSON, I., WILKINSON, D., "Utilitarismo y pandemia”, Bioética, Vol. 34, 2020, pp. 620 632. https://doi.org/10.1111/bioe.12771; Ibidem, p. 8: "La compensación interpersonal de las vidas humanas entre sí con el fin de maximizar unos presuntos beneficios colectivos es incompatible con la primacía de la dignidad humana. [...] El enfoque utilitarista ignora el imperativo categórico kantiano, que ha conformado el concepto universal y secularizado de dignidad humana”.

${ }^{23}$ COMITÉ DE BIOÉTICA DE ESPAÑA, “Informe del Comité de bioética...”, cit., pp. 9-10: “Todas las personas son iguales ante la ley y que, en virtud de ella, tienen derecho a igual protección 10 legal y a beneficiarse de la ley en igual medida sin discriminación alguna. Y se prohíbe en el apartado siguiente toda discriminación por motivos de discapacidad, garantizándose a todas las personas con discapacidad protección legal igual y efectiva contra la discriminación por cualquier motivo. [...] A la luz de estos preceptos, resulta claro que la discapacidad de la persona enferma no puede ser nunca por sí misma un motivo que priorice la atención de quienes carecen de discapacidad".

${ }^{24}$ COMITÉ DE BIOÉTICA DE ESPAÑA, “Informe del Comité de bioética...”, cit. 
de que sean las entidades públicas las que lideren la situación, aunque con el asesoramiento de otros colectivos, dado que son las únicas con capacidad legal para limitar y suspender derechos ${ }^{25}$.

Haciendo referencia a los criterios que se adopten para el triaje, aun pretendiendo ser unificados para todo el Estado, los miembros del Comité recalcan que tendrán que condicionarse a la situación individual de cada paciente ${ }^{26}$.

Por otro lado, también se resalta que la forma de priorización debe ser horizontal entre todos los pacientes que requieren asistencia, más allá de los enfermos de coronavirus. Esto se debe a que, ante esta situación, la atención de los enfermos por coronavirus es una prioridad, pero también lo es la atención de las personas con patologías distintas, ya que el sistema sanitario tiene el mismo deber ético y legal con ambos. Añadido a esto, se plantea también que el criterio de asignación basado en la mera prioridad en el tiempo, es decir, el que llegue antes se atiende antes, tampoco es un criterio que respete los principios de igualdad y de justicia al no incluirse otros elementos valorativos. De este modo, en el informe se plantea: "Priorizar a los colectivos más vulnerables se muestra prima facie como un criterio adecuado",27.

En el informe se considera que los sanitarios y otros profesionales de particular importancia para el tratamiento de la pandemia deben tener preferencia en el acceso a los recursos disponibles. "El principio ético de reciprocidad implica que la sociedad debe apoyar a las personas que asumen una carga o riesgo desproporcionado en la protección del bien público"28.

De este modo, el informe está constituido por un total de 13 páginas en las que se recogen 12 puntos (Tabla 3). En ellos se desarrollan los aspectos comentados en este apartado del estudio. Además de este informe redactado por el Comité de Bioética de España, también existe una nota de prensa en la que se realiza un resumen del informe ${ }^{29}$.

Tabla 3. Puntos del informe del comité de bioética de España sobre la priorización de recursos sanitarios ${ }^{30}$.

\begin{tabular}{|l|l|}
\hline Punto del informe & Descripción \\
\hline Punto 1 & $\begin{array}{l}\text { Descripción del contexto en el que se emite el informe y la } \\
\text { situación excepcional por la que pasaron los miembros del } \\
\text { Comité de Bioética de España. }\end{array}$ \\
\hline Punto 2 & $\begin{array}{l}\text { Desestimación de la elaboración de un informe sobre la } \\
\text { pandemia del coronavirus, ya que este podría llegar a suponer un } \\
\text { estado de confusión en la sociedad. }\end{array}$ \\
\hline
\end{tabular}

${ }^{25}$ Ibidem, p. 6: “[...] sociedades científicas, colegios profesionales, comités de bioética nacional y autonómicos, debemos ponernos urgentemente a disposición de la autoridad pública competente, véase, el Gobierno y el propio Ministerio de Sanidad, para trabajar en unos criterios únicos de priorización a nivel nacional".

${ }^{26} \mathrm{Ibid}$., p. 6: "Entendemos que cualquier criterio o protocolo que se adopte para racionar unos recursos escasos nunca puede aplicarse de manera mecánica o automática: todo ser humano tiene derecho a una consideración personal”.

${ }^{27}$ Ibid., p. 8 .

${ }^{28}$ Ibid., p. 12.

${ }^{29}$ COMITÉ DE BIOÉTICA DE ESPAÑA, “Informe del Comité de Bioética de España sobre los aspectos éticos de la seguridad del paciente y, específicamente, de la implantación de un sistema efectivo de notificación de incidentes de seguridad y eventos adversos", comitedebioetica.es, 28 de abril de 2021, disponible en http://assets.comitedebioetica.es/files/noticias/Nota\%20de\%20Prensa\%20$\% 20$ Informe\%20CBE\%20Seguridad\%20Paciente.pdf

${ }^{30}$ COMITÉ DE BIOÉTICA DE ESPAÑA, “Informe del Comité de bioética...”, cit.; SAVULESCU, J., PERSSON, I., WILKINSON, D., "Utilitarismo y...”, cit. 


\begin{tabular}{|c|c|}
\hline Punto 3 & $\begin{array}{l}\text { Llamada a la colaboración del Ministerio de Sanidad Español } \\
\text { ante la necesidad de la elaboración de unos criterios de } \\
\text { priorización unificados a nivel nacional. }\end{array}$ \\
\hline Punto 4 & $\begin{array}{l}\text { Se describe la naturaleza de la pandemia como una crisis de salud } \\
\text { pública, siendo lo demás (crisis económica, crisis social, etc.) } \\
\text { consecuencias derivadas de esta. }\end{array}$ \\
\hline Punto 5 & $\begin{array}{l}\text { Llamada a la responsabilidad a los ciudadanos y ciudadanas de } \\
\text { España. }\end{array}$ \\
\hline Punto 6 & $\begin{array}{l}\text { Llamada a la responsabilidad a las personas con influencia en la } \\
\text { sociedad (influencers, personajes públicos, famosos, etc.). }\end{array}$ \\
\hline Punto 7 & Llamada a la responsabilidad a los medios de comunicación. \\
\hline Punto 8 & $\begin{array}{l}\text { Se describe el proceso de priorización, incidiendo en que este es } \\
\text { un proceso habitual en centros sanitarios. Sin embargo, se aclara } \\
\text { que la situación en la que se produce esta priorización es } \\
\text { excepcional. }\end{array}$ \\
\hline Punto 9 & $\begin{array}{l}\text { Se divide en } 10 \text { subpuntos en los que se recogen criterios que se } \\
\text { recomienda sean adoptados y otros que sean rechazados en el } \\
\text { proceso de triaje durante esta pandemia. }\end{array}$ \\
\hline Punto 10 & $\begin{array}{l}\text { Reconocimiento a la labor de familias de colectivos vulnerables, } \\
\text { así como a personas que, no siendo personal sanitario, también } \\
\text { cumplen labores esenciales en el cuidado de las personas. }\end{array}$ \\
\hline Punto 11 & $\begin{array}{l}\text { Se remarca la necesidad del reconocimiento de la labor del } \\
\text { personal sanitario, no solo en el punto álgido de la pandemia, } \\
\text { sino en la vida cotidiana de las personas. }\end{array}$ \\
\hline Punto 12 & $\begin{array}{l}\text { Se puede entender la pandemia COVID- } 19 \text { como un suceso que } \\
\text { permite la reflexión y el análisis de las deficiencias para una } \\
\text { mejora del sistema. }\end{array}$ \\
\hline
\end{tabular}

\section{Actuación del Ministerio de Sanidad de España}

El Ministerio de Sanidad de España es el departamento de la Administración General del Estado que asume la propuesta y ejecución de la política del Gobierno en materia de salud, de planificación y asistencia sanitaria, así como el ejercicio de las competencias de la Administración General del Estado para asegurar a los ciudadanos la protección de la salud. El Real Decreto 454/2020, de 10 de marzo es en el que se desarrolla la estructura orgánica básica del Ministerio de Sanidad, y el Real Decreto 139/2020, de 28 de enero, establece la estructura orgánica básica de los departamentos ministeriales. De este modo, las competencias del Ministerio de Sanidad de España son llevadas a cabo por la Secretaría General de Sanidad, encargada de la Dirección General de Salud Pública, Calidad e Innovación, la Dirección General de Cartera Común de Servicios del Sistema Nacional de Salud y Farmacia, la Dirección General de Ordenación profesional y la Delegación del Gobierno para el Plan Nacional sobre Drogas, y la Subsecretaría de Sanidad, encargada de la Secretaría General Técnica ${ }^{31}$.

La actuación más relevante del Ministerio de Sanidad de España en el contexto de la pandemia COVID-19 tiene lugar después de que entidades externas a la administración pública y el Comité de Bioética de España emitan informes que tienen como finalidad establecer unos criterios en el proceso de triaje. De esta manera, se podría considerar que la primera intervención

31 MINISTERIO DE SANDIDAD DE ESPAÑA, página web oficial disponible en https://www.mscbs.gob.es/. Consultado el 22/05/2021 
del Ministerio de Sanidad tuvo lugar con la respuesta a la carta redactada por el Comité de Bioética de España el día 4 de marzo de 2020, en la que este Comité manifiesta la preocupación por los criterios dispares de priorización que se estaban llevando a cabo en los Centros Sanitarios Españoles. En esta respuesta, el Ministerio de Sanidad pide al Comité de Bioética de España que sean ellos los que redacten un primer informe sobre el proceso de priorización, teniendo en cuenta los aspectos bioéticos más relevantes.

Es el 25 de marzo de 2020 cuando se emite el informe oficial por parte del Comité de Bioética en el que se recogen los criterios que se aconsejan seguir para un proceso de triaje justo y equitativo para los españoles y españolas. Finalmente, es el día 3 de abril de 2020 cuando el Ministerio de Sanidad emite el informe oficial denominado "Informe del Ministerio de Sanidad sobre los aspectos éticos en situaciones de pandemia: El SARS-CoV-2". La finalidad de este informe según el Ministerio de Sanidad es la de: "[...] ofrecer un conjunto de conclusiones y recomendaciones que ayuden a la toma de decisiones en la aplicación de medidas terapéuticas y de cuidados a pacientes afectados por COVID-19, en una situación de pandemia marcada por la limitación de recursos" $"$.

El primer punto que desarrolla este informe es la Introducción. En ella se hace referencia a la necesidad del uso de la ética como herramienta para hacer frente a la pandemia. Además, se hace alusión a la importancia de asumir las restricciones propuestas por el Gobierno de España con el objetivo de superar esta crisis sanitaria en la mayor brevedad posible ${ }^{33}$.

Añadido a esto, se comenta la importancia de que la toma de decisiones con respecto a esta situación de extrema gravedad no debe ser asumida individualmente por parte de ciertos colectivos y entidades científicas, sino que es algo que compete a toda la sociedad. Afirma que, por ello, para la redacción de este informe han tenido en cuenta otros pronunciamientos de otras entidades $^{34}$.

Para finalizar con el punto de Introducción de este informe, el Ministerio de Sanidad asume su responsabilidad en esta situación excepcional: "En nuestro caso, en este estado de alarma corresponde, con plena legitimidad democrática, al Gobierno de la Nación, a través del Ministerio de Sanidad, asumir la responsabilidad política de adoptar criterios, recomendaciones y decisiones, según sea oportuno, unificadoras, constructivas y, en su caso, tranquilizadoras, dirigidas a los profesionales sanitarios y no sanitarios afectados, a los pacientes y, en suma, a toda la sociedad"35.

En el segundo punto de este informe denominado Pruebas de Infección por el virus: Derecho y obligación, se desarrollan unos criterios de priorización en cuanto a la realización de pruebas diagnósticas para la infección del virus SARS-CoV-2. Se plantean estos criterios, ya que estas pruebas en el momento de redacción del informe no eran suficientes. Las personas que tendrían en un primer momento el derecho a acceder a estas pruebas serían los profesionales sanitarios asistencialmente implicados con pacientes y otros empleados que también estén en contacto con ellos, como, por ejemplo, agentes de los cuerpos de policía y personal del ejército.

\footnotetext{
32 MINISTERIO DE SANIDAD DE ESPAÑA, "Informe del Ministerio de Sanidad sobre los aspectos éticos en situaciones de pandemia: El SARS-CoV-2”, p. 1, mscbs.gob.es, 3 de abril de 2020.

${ }^{33}$ Ibidem, p. 5: "[...] han de asumirse las restricciones que pueden sufrir los derechos fundamentales y las libertades públicas de los ciudadanos, pero siempre dentro del principio de proporcionalidad y sin que quede comprometido el núcleo básico o contenido esencial de aquéllos, como ha subrayado el Tribunal Constitucional”.

${ }^{34}$ Ibid., p. 5: "Por esta razón hemos consultado informes y opiniones diversos de nuestro país, como, entre otros, los de la Sociedad Española de Medicina Intensiva, Crítica y Unidades Coronarias (SEMICYUC), de la Comisión Central de Deontología de la Organización Médica Colegial, del Comité de Bioética de España; así como de otros órganos consultivos internacionales o europeos y sociedades científicas extranjeras o internacionales".

${ }^{35}$ Ibid.
} 
También tendrían acceso prioritario las personas que estén relacionadas con ciudadanos de mayor riesgo, como son el personal de residencias, centros de atención a personas mayores y dependientes, residencias de menores, internados en centros penitenciarios y similares, y las personas que hayan podido estar en contacto próximo con otras personas infectadas por el virus ${ }^{36}$.

Sin embargo, en este mismo punto se aclara que esta priorización se lleva a cabo debido a la situación de escasez de pruebas diagnósticas, pero que no es una situación permanente. En el momento en el que la disponibilidad fuera abundante, el derecho de los ciudadanos pasaría a ser un deber, es decir, las personas tendrían la obligación de realizarse las pruebas diagnósticas por el bien de la salud pública, siempre dentro de los límites que marca el Principio de Proporcionalidad. Para finalizar con este punto, se afirma que: "A la vista de un resultado positivo del test (y su confirmación en caso de duda), se entraría en la imposición de un aislamiento domiciliario o el ingreso en un centro sanitario u otro de seguridad, según corresponda ${ }^{37}$.

El punto número 3 desarrollado en este informe y con título Prioridades en la admisión $y$ tratamiento de pacientes sospechosos de ser portadores, se inicia haciendo referencia al derecho constitucional recogido en el Artículo 43 de la Constitución Española, en el que se desarrolla el deber de asistencia de los profesionales en su actividad asistencial que tienen todos los españoles y ciudadanos extranjeros residentes en el territorio nacional. Sin embargo, ante esta situación de demanda masiva y escasez de recursos, se afirma que se puede producir una reducción del disfrute de este derecho, aunque transitoria. Se plantea que esta reducción se debe a la priorización necesaria de los individuos potencialmente más expuestos al contagio o ya infectados ${ }^{38}$.

El punto número 4 de este informe se denomina Criterios de admisión de pacientes con síntomas graves en unidades de cuidados intensivos y aplicación de ventilación mecánica asistida. En este punto se desarrollan los criterios que debe seguir el personal sanitario de las Unidades de Cuidados Intensivos (UCIs). Se establece también una priorización, ya que la demanda de recursos en UCIs es superior a los recursos existentes. Además, se afirma que no debe recaer únicamente sobre el personal sanitario la identificación de los criterios que sean adecuados para la toma de decisiones relacionadas con los tratamientos vitales requeridos por algunos pacientes. Sumado a esto, se añade que en estas situaciones se puede crear un dilema entre la mentalidad utilitarista y la humanitarista, y, por lo tanto, estos criterios de priorización deben ser objetivos, generalizables, transparentes, públicos, consensuados, orientadores, claros y sencillos $^{39}$. En la Tabla 4 se recogen los criterios desarrollados para la admisión de pacientes en UCI y para la aplicación de ventilación mecánica asistida durante la pandemia COVID-19. 
En este punto se explica también que únicamente será legítimo el uso de estos criterios de priorización siempre y cuando se hayan agotado todas las posibilidades existentes para disponer de los recursos asistenciales necesarios y para optimizar el uso de los disponibles. Aclara que, dada esta situación, son los poderes públicos los que tienen la obligación de asegurar al máximo la planificación de los recursos asistenciales: "Debe garantizarse la optimización en la planificación de dichos recursos asistenciales a nivel local, autonómico y estatal, pues aquí también resulta relevante la solidaridad institucional" ${ }^{40}$. Será el equipo médico responsable del paciente el que deberá asumir las implicaciones de sus decisiones con respecto a la priorización de recursos, aunque se recomienda que se soliciten y reciban orientaciones del comité de ética asistencial del mismo centro sanitario. Este punto finaliza con la indicación de que no se debe olvidar la necesidad de atender a pacientes con enfermedades graves similares, pero de origen distinto al virus.

Tabla 4. Criterios propuestos por el ministerio de España en su informe del 23 de abril de $2020^{41}$.

\begin{tabular}{|c|c|}
\hline Orden de los criterios & Desarrollo del criterio \\
\hline Primero & $\begin{array}{l}\text { No discriminación por ningún motivo ajeno a la } \\
\text { situación patológica del paciente y a las } \\
\text { expectativas objetivas de supervivencia }\end{array}$ \\
\hline Segundo & $\begin{array}{l}\text { El principio de máximo beneficio en la } \\
\text { recuperación de vidas humanas, que debe } \\
\text { compatibilizarse con la continuación de la } \\
\text { asistencia iniciada de forma individual de cada } \\
\text { paciente }\end{array}$ \\
\hline Tercero & $\begin{array}{l}\text { Gravedad del estado de enfermedad del paciente } \\
\text { que evidencie la necesidad de cuidados intensivos } \\
\text { (asistencia en unidades de cuidados intensivos y } \\
\text { acceso a ventiladores mecánicos o, en su defecto, } \\
\text { acceso en todo caso a estos últimos) }\end{array}$ \\
\hline Cuarto & $\begin{array}{l}\text { Expectativas objetivas de recuperación del paciente } \\
\text { en el corto plazo a su estado previo de salud, } \\
\text { teniendo en cuenta la concurrencia o no de } \\
\text { patologías graves acompañantes que evidencien un } \\
\text { pronóstico fatal (enfermos terminales con } \\
\text { pronóstico de irreversibilidad, estado de coma } \\
\text { irreversible, etc.), aunque pueda comportar una } \\
\text { atención clínica añadida }\end{array}$ \\
\hline Quinto & $\begin{array}{l}\text { Orden temporal de entrada en contacto con el } \\
\text { sistema de salud, consistente en este caso en la data } \\
\text { de ingreso en el centro, con el fin de objetivar el } \\
\text { punto de partida de los pacientes de los que se } \\
\text { responsabiliza el sistema. Sin embargo, este } \\
\text { criterio nunca debe anteponerse a los anteriores, } \\
\text { pues podría provocar la preferencia de pacientes de } \\
\text { menor urgencia, atendiendo a la gravedad de su } \\
\text { situación, o de pacientes sin ningún pronóstico } \\
\text { favorable sobre su recuperación }\end{array}$ \\
\hline
\end{tabular}

paciente en particular, valorando dentro de ese marco general de principios rectores, la singularidad y la individualidad de cada persona".

${ }^{40}$ Ibid.

${ }^{41}$ Ibid. 
El punto número 5 de este informe, Decisiones sobre cuidados intensivos de pacientes vulnerables, responde a determinados planteamientos de medios de comunicación, ciertos foros científicos, en los que se proponen asumir criterios como el de la edad para la priorización de pacientes. La respuesta del Ministerio de Sanidad a estos planteamientos se resume en el siguiente fragmento de este punto del informe: "Resulta procedente poner de manifiesto la absoluta proscripción de empleo de criterios fundados en la discriminación por cualquier motivo con la finalidad de priorizar pacientes en dichos contextos. En este sentido, excluir a pacientes del acceso a determinados recursos asistenciales o a determinados tratamientos (por ejemplo, aplicar dicha limitación a toda persona de edad superior a 80 años) resulta contrario, por discriminatorio, a los fundamentos mismos de nuestro estado de derecho (art. 14 Constitución española) [...] Una argumentación de la misma naturaleza cabe desarrollar con el fin de proscribir cualquier otra discriminación en el acceso a los recursos asistenciales escasos con ocasión de una pandemia por motivos tales como la discapacidad en cualquiera de sus manifestaciones"42.

En el punto número 6, Disponibilidad y reclutamiento de personal sanitario, se desarrolla la necesidad de reclutamiento de personal sanitario debido a la gran demanda ejercida por esta pandemia y debido también a la reducción de personal sanitario por contagio por este virus. De este modo, en este punto se resalta la necesidad de proporcional las máximas garantías en lo relativo a la idoneidad del personal incorporado para la asunción de las tareas asistenciales que deba desarrollar ${ }^{43}$.

Con este informe del Ministerio de Sanidad desarrollado en 12 páginas y en el que se recogen los 6 puntos explicados con anterioridad, el Gobierno de España da una respuesta a la necesidad de unificación de los criterios de priorización en los centros sanitarios del territorio español. Como se ha señalado anteriormente, estos criterios son generales y deben ser evaluados y orientados a la situación individual de cada paciente. Para ello el equipo médico de cada paciente debe apoyarse en las recomendaciones de comités éticos asistenciales de los centros sanitarios, así como en criterios científicos. Cabe destacar que, en el momento en el que no se requiera una priorización de pacientes tan exhaustiva, será necesario que el personal sanitario se rija por los criterios de priorización rutinarios y por su deber de asistencia y salvaguarda de la salud de las personas, recogido en el Artículo 43 de la Constitución Española.

\section{TRIAJE EN CENTROS SANITARIOS EN OTROS PAÍSES DURANTE LA PANDEMIA COVID-19}

Durante el transcurso de la pandemia han sido numerosos los países que se han visto en escasez de recursos médicos, así como de atención sanitaria. Por ello, al igual que España, han tenido que hacer frente a situaciones dramáticas donde el triaje ha supuesto un papel muy relevante: asignación de camas de UCI, respiradores o cuidados intensivos. Las maneras de afrontar estas situaciones extremas no han sido aplicadas de manera uniforme en todos los países, puesto que los recursos en cada uno de ellos y el momento en el que fueron azotados por esta

\footnotetext{
${ }^{42}$ Ibid., p. 9.

${ }^{43}$ Ibid., p. 10: "Se prevén la realización de censos del personal facultativo especialista en cuidados críticos (pudiendo incluir a aquellos en situación de desempleo, recién jubilados, dedicados a otras tareas, profesionales no comunitarios pendiente de convalidación de títulos, etc.), censos en cada hospital de otros facultativos de plantilla o residentes de otras especialidades que pudieran tener capacidad de asistencia a pacientes menos graves, etc. Previsiones similares atinentes al posible reclutamiento de nuevos profesionales deberán establecerse con respecto al personal de enfermería y al personal auxiliar".
} 
pandemia han sido distintos. De este modo, cada uno ha delimitado unas pautas de toma de decisiones y de triaje distintos ${ }^{44}$.

Nos centraremos en dos países con características similares a España: Francia e Italia, para observar cómo ha sido el transcurso de la pandemia en estos países y cuáles han sido sus puntos clave a la hora de afrontarla.

\section{Proceso de triaje en Italia}

En Italia, la rápida expansión del virus hizo que se generase una situación de emergencia sanitaria que pronto se catalogó de catástrofe. Esta situación forzó a la implantación de un duro sistema de triaje que provocó una ruptura del sistema sanitario italiano y generó un cambio de la relación médico-paciente. Al igual que en España, las sociedades científicas y los comités de ética, establecieron guías para el triaje con la finalidad de ayudar al médico en la toma de decisiones. Concretamente, se publicaron dos documentos por parte de las entidades científicas que han sido objeto de debate. En Italia fue publicado por la Società Italiana di Anestesia, Analgesia, Rianimazione e Terapia Intensiva (SIAARTI) y, en España, por SEMICYUC como se refleja en el apartado anterior. Ambos documentos se centraron en el principio de justicia distributiva de los recursos sanitarios adecuada a la falta de estos. Este principio excluye al igualitarismo donde se distribuyen equitativamente los recursos sin hacer comparativas entre pacientes. En este sentido, SIAARTI incluyó en sus recomendaciones una edad límite de acceso a los cuidados intensivos lo cual supuso una gran oleada de críticas sociales por seguir una lógica aparentemente utilitarista. En contraposición, en España ante una situación donde dos personas requieran cuidados intensivos, se elegiría a aquella con una mayor calidad de vida posterior a su tratamiento ${ }^{45}$.

Cabe destacar que ambos documentos sufrieron críticas desde posiciones oficiales. Por ejemplo, en Italia, la Orden de Médicos intervino comunicando su discrepancia con respecto a la aplicación del principio de justicia distributiva, puesto que para ellos el Código de la Ética Médica era "su guía" donde se especificaba que los pacientes son iguales y no debían discriminarse. Ante esta disparidad de opiniones el Comitato Nazionale per la Bioetica (CNB) intervino con un dictamen el cual mostraba poca aceptación al principio de justicia distributivo tal y como lo había descrito SIAARTI. Ante una situación como la actual, la grave escasez de recursos, el CNB evaluó el criterio clínico como el punto de referencia más adecuado para la asignación de los mismos recursos, por tanto, cualquier otro criterio de selección, como edad, sexo, condición y el rol social, la etnia, la discapacidad, la responsabilidad por los comportamientos que contribuyen a la patología, los costos, es considerado éticamente inaceptable por el Comité. Así, su propuesta incluye al principio de justicia distributiva, pero desde un punto de vista personalista y evitando a toda costa caer en un principio utilitarista ${ }^{46}$.

Como hemos visto, en una situación de emergencia sanitaria existe una tensión moral generada por el hecho de que dos principios éticos: justicia distributiva e igualitarismo se enfrentan entre sí. Es más, la necesidad de cambiar el modelo igualitario tan común en la práctica habitual médica genera una presión y angustia a los médicos no acostumbrados a la toma de decisiones tan complejas como las vividas durante este periodo. Esta angustia se refleja en una

\footnotetext{
44 ORFALI, K., "What Triage Issues Reveal: Ethics in the COVID-19 Pandemic in Italy and France", Bioethical Inquiry, Vol 17, 2020, pp. 675-679. https://doi.org/10.1007/s11673-020-10059-y

${ }^{45}$ FAGGIONI, M.P., GONZÁLEZ-MELADO, F.J., DI PIETRO, M.L., "National health system cuts and triage decisions during the COVID-19 pandemic in Italy and Spain: ethical implications.", J Med Ethics, Vol 47, 2021, p. 300-307, disponible en https://jme.bmj.com/content/medethics/47/5/300.full.pdf

${ }^{46}$ Ibidem.
} 
frase pronunciada por un médico italiano en primera línea: "Dobbiamo decidere chi dovrebbe morire e chi mantenere in vita" ${ }^{\prime 4}$.

\section{Proceso de triaje en Francia}

En Francia, al igual que en España e Italia se carecía de un protocolo de actuación frente a la situación de emergencia provocada por el virus SARS-CoV-2. Por tanto, se elaboró un comunicado por parte de Société Française d'Anesthésie et de Réanimation (SFAR) cuyo contenido era parecido al de las sociedades científicas que se pusieron de manifiesto en España e Italia. Su objetivo era minimizar el número de muertes y maximizar los años de vida salvados. Más tarde el Comité Nacional de Bioéthique Français denotó su apoyo a los médicos en la toma de decisiones ${ }^{48}$.

Por tanto, como se ha ido observando, la intervención de los Comités de Bioética a nivel nacional cobró un papel muy importante a la hora de ayudar a la sociedad médica y científica en los tres países descritos. No obstante, su colaboración podría haber sido más temprana, estableciendo protocolos de triaje y, evitando así delegar demasiadas responsabilidades en el personal sanitario de primeria línea y el debate ético-social sobre sus actuaciones. Este hecho lleva a aprender, ante el advenimiento de una nueva pandemia, que los profesionales de la salud deben tener reglas claras y justas a seguir ${ }^{49}$.

\section{OTROS ÁMBITOS DEL TRIAJE DURANTE LA PANDEMIA}

Durante la pandemia producida por el virus SARS-CoV-2 no sólo ha sido necesario el establecimiento de un protocolo de triaje en centros hospitalarios para la atención asistencial de las personas, sino que también, una vez obtenida la vacuna contra este virus, ha sido necesario establecer un protocolo de triaje para la vacunación de los ciudadanos y ciudadanas españoles. Las vacunas son la herramienta más potente para la protección de las personas frente a este virus. Sin embargo, durante el desarrollo de cualquier vacuna, es fundamental tener en cuenta que la protección de las vidas humanas debe ser la prioridad. De este modo, el desarrollo de la vacuna contra el coronavirus ha sido un suceso sin precedentes: se ha desarrollado en un tiempo récord, se han desarrollado varias vacunas diferentes, los estudios en personas se han realizado en el menor tiempo posible, el proceso de vacunación se encuentra en marcha en numerosos países etc. El estado del proceso de vacunación en España es de un 78,6\% de personas vacunadas con pauta completa, y un $80,2 \%$ de personas vacunadas con al menos una dosis (Figura 3A). Las distintas vacunas que están y estarán disponibles en España para la vacunación se recogen en la Figura $3 \mathrm{~B}^{50}$.

\footnotetext{
${ }^{47}$ LISA ROSENBAUM, M.D., "Facing Covid-19 in Italy — Ethics, Logistics, and Therapeutics on the Epidemic's Front Line", The new England journal of medicine, 14 de mayo de 2020, disponible en https://www.nejm.org/doi/full/10.1056/nejmp2005492

${ }^{48}$ ORFALI, K., "What Triage Issues Reveal: Ethics...," cit.

49 Ibidem.

${ }^{50}$ WIBAWA, T., "COVID-19 vaccine research and development: ethical issues", Trop Med Int Health, Vol 26, Num 1, 2021, pp. 14-19. https://dx.doi.org/10.1111\%2Ftmi.13503
} 


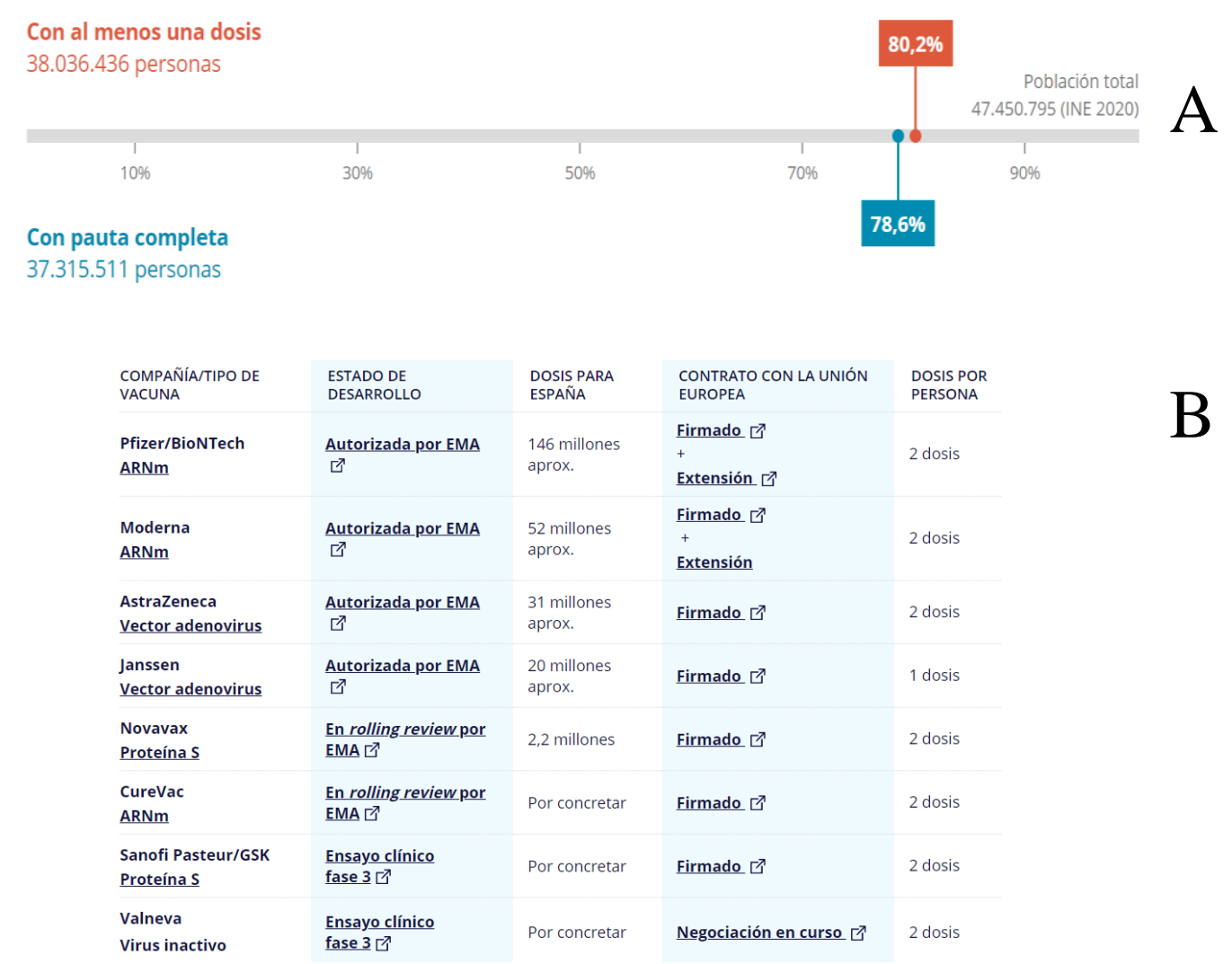

Figura 3. (A) Estado de la vacunación a día 30-10-2021. (B) Vacunas que están o estarán disponibles en España. Imágenes tomadas de la página https://www.vacunacovid.gob.es/. Consultado 01/11/2021

El proceso de vacunación en España se encuentra dividido en 4 etapas. La etapa 0 constituye el momento en el que se desarrolló la vacuna, se autorizó y se evaluó. La etapa 1 es en la que ya había algunas dosis disponibles para la vacunación. En esta etapa se vacunaron los grupos considerados prioritarios, como son residentes y personal en centros de mayores y de atención a grandes dependientes, personal sanitario y sociosanitario de primera línea, otro personal sanitario y sociosanitario y grandes dependientes no institucionalizados. En la etapa 2, aumentó el número de dosis disponibles y se vacunó a otros grupos prioritarios, como son mayores de 80 años, personas entre 70 y 79 años y personas con condiciones de muy alto riesgo, personas entre 60 y 69 años, otro personal sanitario y sociosanitario, trabajadores con una función social esencial y personas entre 50 y 59 años. En la etapa 3 la vacuna se encuentra ampliamente disponible. Su inicio tuvo lugar en junio de 2021 y continúa hasta el día de hoy. En el momento actual, se puede considerar que la vacunación de los grupos priorizados inicialmente casi está completada, y la pauta de vacunación está centrada fundamentalmente en el grupo de personas de 12 a 19 años y en aquellos que todavía no se hayan vacunado del resto de grupos. Además, se ha comenzado con la administración de una tercera dosis en el grupo de personas con condiciones de muy alto riesgo a partir de 12 años y de una dosis de recuerdo en los internos de residencias de mayores. A finales de octubre se ha comenzado la administración de una dosis de recuerdo de vacuna de ARNm en la población mayor de 70 años. A partir del 15 de noviembre y priorizando los grupos de vacunación de la Estrategia Nacional de Vacunación, comienza la administración 
de una dosis de recuerdo con ARNm a aquellas personas vacunadas con Janssen. Toda esta información se recoge en la Figura $4^{51}$.

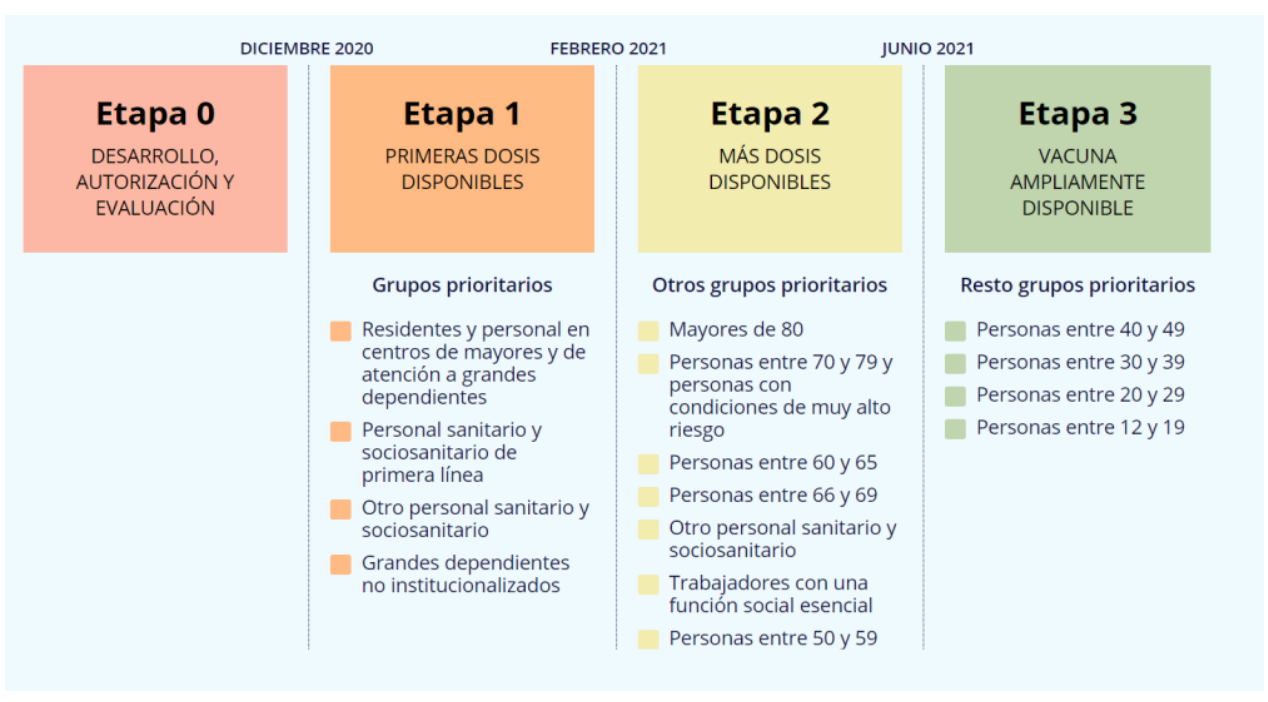

Figura 4. Etapas proceso de vacunación en España. Imagen tomada de la página https://www.vacunacovid.gob.es/. Consultado: 01/11/21.

Ante la necesidad del establecimiento de un protocolo de vacunación por la escasez de vacunas, el Comité de Bioética de España redactó un informe el 14 de diciembre de 2020, titulado "Declaración del Comité de bioética de España sobre la estrategia de vacunación frente a la covid19 y, en especial, sobre la priorización de la vacunación" ${ }^{52}$. En este informe se recoge un total de 6 puntos:

En el primer punto se afirma que la vacuna frente al virus SARS-CoV-2 es la herramienta más eficaz para luchar contra este virus. Se destaca también que la inmunización por contagio no es una estrategia segura, ya que los efectos negativos de esta enfermedad pueden llegar a ser devastadores. Añadido a esto, se afirma que el confinamiento y el recorte de libertades tampoco es una estrategia que se pueda seguir durante un gran periodo de tiempo y, por lo tanto, no sería eficaz para terminar con la pandemia. Se señala que es necesario establecer unos criterios de priorización en la vacunación, ya que las vacunas que inicialmente estarán disponibles en España no serán suficientes para el total de la población. Sin embargo, a medida que el número de vacunas sea mayor, se tenderá a garantizar la universalidad de la vacunación en España ${ }^{53}$.

En el segundo punto se afirma que un modelo mixto de priorización de los recursos sería el más adecuado, prestando especial atención a la vulnerabilidad: "[...] la priorización en la distribución de las vacunas debe llevarse a cabo con especial atención no solo a criterios científicos, clínicos y económicos, sino también éticos y legales. Y a estos efectos, los principios

\footnotetext{
${ }^{51}$ GOBIERNO DE ESPAÑA, "Estrategia de vacunación COVID-19”, disponible en https://www.vacunacovid.gob.es/. Consultado: 25/05/2021

52 COMITÉ DE BIOÉTICA DE ESPAÑA, "Declaración del comité de Bioética de España sobre la estrategia de vacunación frente a la covid-19 y, en especial, sobre la priorización de la vacunación.”, 14 de diciembre de 2020, disponible en http://assets.comitedebioetica.es/files/documentacion/Declaracion\%20del\%20CBE\%20\%20Estrategia\%20priorizacion\%20vacunacion\%20frente\%20COVID19.pdf

${ }^{53}$ Ibidem.
} 
de igualdad, equidad, necesidad, beneficio social y reciprocidad tienen un significado específico en el contexto del acceso a la atención de la salud" ${ }^{\prime 54}$.

En el punto tres se hace referencia al Informe sobre los requisitos ético-legales en la investigación con datos de salud y muestras biológicas en el marco de la pandemia de Covid-19 del Comité de Bioética de España, emitido el 28 de abril de 2020, en el que ya se hacía referencia a la dificultad que se establecería a la hora del acceso a las vacunas y a la necesidad de protocolos de priorización de la vacunación, ya que existe un interés a nivel mundial al acceso a las vacunas ${ }^{55}$.

En el punto cuatro se explica que no existe un informe propio del Comité de Bioética de España sobre los aspectos en la priorización de la vacunación, ya que el propio Comité fue invitado a participar en el grupo denominado Grupo de Trabajo técnico sobre priorización en el acceso a las vacunas frente a Covid-19, que se estaba constituyendo en el marco de la Subdirección General de Promoción de la Salud y Vigilancia en Salud Pública del Ministerio. Resaltan que en las propias medidas tomadas por el Ministerio ya estaría incluida la perspectiva Bioética $^{56}$.

En el punto cinco, el Comité de Bioética de España agradece el ofrecimiento a participar en el proceso de establecimiento de unos protocolos de priorización de un recurso sanitario tan importante y en un contexto tan dramático. Elogian el trabajo del Grupo de Trabajo técnico sobre priorización en el acceso a las vacunas frente a COVID-19 y transmiten su satisfacción porque se tengan en cuenta y se incluyan los principales criterios bioéticos aceptados universalmente, así como los principios, valores y derechos consagrados en la Constitución Española ${ }^{57}$.

En el punto seis de este informe recuerdan que no sólo son las entidades públicas y los altos cargos los que deben tomar medidas ante esta pandemia, sino que también son los ciudadanos y ciudadanas españoles los que deben ejercer ejemplarmente su responsabilidad en el cumplimiento de las medidas que evitan contagio ${ }^{58}$.

De esta manera, el informe redactado por el Grupo de Trabajo técnico sobre priorización en el acceso a las vacunas frente a COVID-19 (Subdirección General de Promoción de la Salud y Vigilancia en Salud Pública del Ministerio), Estrategia de vacunación frente a COVID-19, está constituido por un total de 18 páginas en las que se recogen 8 puntos. Sin embargo, el punto que compete a los aspectos éticos de la priorización de la vacunación es el punto 2 y será el que se desarrolle a continuación ${ }^{59}$.

En este punto se hace referencia a la escasez inicial de vacunas para la población total de España, lo que justifica la necesidad de un proceso de priorización. Se afirma que serán tres las vacunas disponibles en España y que, aunque presentan diferentes características en cuanto a su eficacia, logística y perfiles de población en las que han sido ensayadas, han pasado todos los requisitos necesarios para poder ser administradas a las personas. Las diferencias que pueden existir entre las vacunas son las que marcan la priorización de estas para determinadas personas:

\footnotetext{
${ }^{54}$ Ibid., p. 2.

${ }^{55}$ Ibid.

${ }^{56} \mathrm{Ibid}$.

${ }^{57}$ Ibid.

${ }^{58}$ Ibid., p. 3: “[...] A nadie se le escapa que tan grave como la pandemia es la 'infodemia o infoxicación' que vivimos, que difunde informaciones falsas y escandalosas sobre la enfermedad y las vacunas, sembrando el desconcierto y la alarma entre los ciudadanos".

${ }^{59}$ GRUPO DE TRABAJO TÉCNICO DE VACUNACIÓN COVID-19 DE LA PONENCIA DE PROGRAMA Y REGISTRO DE VACUNACIÓN, "Estrategia de vacunación frente a COVID19 en España", Consejo interterritorial sistema nacional de salud, Actualización 3, 9 de febrero de 2021.
} 
"Por tanto, urge reforzar la protección de los más vulnerables y, por ello, la elección de la vacuna o vacunas a aplicar no puede establecerse por elecciones individuales, sino que debe basarse en la eficacia y la indicación de la o las vacunas para los diferentes grupos de población"60.

Los principios éticos que se tienen en cuenta para la priorización de las vacunas en este informe son: el principio de necesidad, el principio de equidad y el principio de reciprocidad. El principio de necesidad indica cómo, cuándo y a quién hay que distribuir las vacunas en el contexto de pandemia actual. El principio de equidad exige tener en cuenta las vulnerabilidades, desigualdades, riesgos y necesidades de los grupos, tanto para el momento de la vacunación como para la elección de la vacuna. El principio de reciprocidad exige proteger especialmente a quienes soportan importantes riesgos y cargas adicionales por la COVID-19 por estar dedicados a salvaguardar el bienestar de los demás, incluida la salud ${ }^{61}$.

De esta manera, en este informe se concluye que: "Evaluando los riesgos de exposición, transmisión, morbilidad grave y mortalidad, a la vista de los principios de necesidad, equidad y reciprocidad, se asume que las vacunas que presenten, en el estado actual de la evidencia científica, mayor eficacia deben dirigirse a la población cuya vida e integridad se vea más expuesta"62.

\section{CONCLUSIÓN}

La intensificación del triaje y la priorización de los recursos sanitarios ha sido un punto clave para sobrellevar la pandemia, tanto en España como en muchos países con características similares. No obstante, la falta de costumbre por parte de la comunidad sanitaria a aplicar unos criterios de triaje en situaciones tan extremas como las acontecidas, ha llevado a cuestionarse si realmente es ese su papel; o si, por el contrario, el reparto de los recursos sanitarios debería realizarse en conjunto con las personalidades de la bioética de cada país.

Como hemos ido observando durante esta revisión, las comunidades científicas y sanitarias de varios países fueron las primeras en actuar frente a la emergencia de la situación, teniendo que decidir el acceso a los recursos sanitarios existentes, entre ellos, la entrada en UCI.

Consideramos que algunos de estos dilemas, como quién accedía en un primer momento a la Unidad de Cuidados Intensivos, fueron mal planteados inicialmente, puesto que se emplearon algunos criterios bastante cuestionables desde el punto de vista bioético. Un ejemplo podría ser el criterio de la edad. Este no debería ser un impedimento para el acceso a los recursos sanitarios, puesto que cada caso ha de ser evaluado de manera individual, considerando diversos puntos, entre ellos, la probabilidad de supervivencia del paciente tras una intervención tan exhaustiva. No obstante, sí pensamos que este criterio debe considerarse de manera secundaria, ya que a la hora de evaluar conjuntamente quién entra a UCI o no, los años de supervivencia podrían ser un factor crucial cuando hay escasez de recursos. Sin embargo, las consecuencias asociadas a este tipo de decisiones se pueden comparar con una moneda: siempre hay dos caras. En el caso de la aplicación del criterio de la edad como único filtro, atendiendo a los años de supervivencia, instó a la población de mayor edad a desconfiar de la racionalización de recursos. Otro criterio comparable al criterio de la edad podría ser el de utilidad social. Creemos que, en determinadas situaciones, como la expuesta en esta revisión, estos criterios deben ser tenidos en cuenta y contemplados. Sin embargo, debe evitarse la visión utilitarista de las personas y los recursos.

\footnotetext{
${ }^{60}$ Ibidem, p. 5.

${ }^{61}$ Ibid.

62 Ibid., p. 6.
} 
Toda esta situación anteriormente mencionada llevó al desgaste psicológico del personal sanitario el cual no contaba con unos criterios unificados. Además, la oleada de críticas por parte de la sociedad no tardó en aparecer, puesto que algunas de las medidas tomadas hasta ese momento podrían llegar a marginar a las minorías al considerarse utilitaristas. Fue así como el Comité de Bioética de España y otros comités de bioética extranjeros, decidieron elaborar unos criterios uniformes con la finalidad de apoyar al personal sanitario y paliar la falta de recursos de la mejor manera posible.

Finalmente, la lucha contra el virus SARS-CoV2 ha desembocado en un nuevo dilema ético: la priorización en el sistema de vacunación. No obstante, este proceso no ha sido tan complicado, puesto que desde el principio ha habido unos criterios éticos que adoptar a la hora de repartir unas dosis que eran escasas. Sin embargo, actualmente este dilema está solventado y existe un porcentaje considerable de la población ya vacunada. Aun siendo esta la situación actual, el aprendizaje que podemos sacar de este suceso es que los Comités de Bioética deben estar presentes a la hora de tomar decisiones tan complejas como las acontecidas y que, aunque los criterios que se establezcan puedan variar dependiendo de la situación, estos siempre deben permanecer como un recurso accesible para todo el personal sanitario.

\section{BIBLIOGRAFÍA}

- ALONSO, A., "Las bases de datos de ADN de interés forense", en CRESPILLO, M.C., BARRIO, P.A. (Ed.), Genética forense: del laboratorio a los tribunales, Ediciones Díaz de Santos, Madrid, 2019, pp. 425-443.

- BEAUCHAMP, T.L., "Métodos y principios en ética biomédica", Revista de Ética Médica, Vol. 29, 2003; pp. 269-274. https://jme.bmj.com/content/29/5/269

- BRAVEMAN, P., "Disparidades en salud y equidad en salud: conceptos y medición.", Annual Review of Public Health, Vol. 27, Núm. 1, 2006, pp. 167-194. https://doi.org/10.1146/annurev.publhealth.27.021405.102103

- CHRISTIAN, M. D., "Triage”, Critical care clinics, Vol. 35, Núm. 4, 2019, pp. 575-589. https://doi.org/10.1016/j.ccc.2019.06.009

- COMISIÓN CENTRAL DE DEONTOLOGÍA DEL CONSEJO GENERAL DE COLEGIOS OFICIALES DE MÉDICOS, "Informe de la Comisión Central de Deontología en relación a la priorización de las decisiones sobre los enfermos en estado crítico en una catástrofe sanitaria.", cgcom.es, 23 de marzo de 2020. Disponible en https://www.cgcom.es/informede-la-comisi\%C3\%B3n-central-de-deontolog\%C3\%ADa-en-relaci\%C3\%B3n-lapriorizaci\% $3 \%$ B3n-de-las-decisiones-sobre

- COMITÉ DE BIOÉTICA DE ESPAÑA, Página web oficial disponible en http://www.comitedebioetica.es/

- COMITÉ DE BIOÉTICA DE ESPAÑA, "Declaración del comité de Bioética de España sobre la estrategia de vacunación frente a la covid-19 y, en especial, sobre la priorización de la vacunación.", 14 de diciembre de 2020, disponible en http://assets.comitedebioetica.es/files/documentacion/Declaracion\%20del\%20CBE\%20\%20Estrategia\%20priorizacion\%20vacunacion\%20frente\%20COVID19.pdf

- COMITÉ DE BIOÉTICA DE ESPAÑA, “Informe del Comité de bioética de España sobre los aspectos bioéticos de la priorización de recursos sanitarios en el contexto de la crisis del coronavirus", comitedebioetica.es, 25 de marzo de 2020, disponible en 
http://assets.comitedebioetica.es/files/documentacion/Informe\%20CBE-

\%20Priorizacion\%20de\%20recursos\%20sanitarios-coronavirus\%20CBE.pdf

- COMITÉ DE BIOÉTICA DE ESPAÑA, "Informe del Comité de Bioética de España sobre los aspectos éticos de la seguridad del paciente y, específicamente, de la implantación de un sistema efectivo de notificación de incidentes de seguridad y eventos adversos", comitedebioetica.es, 28 de abril de 2021, disponible en http://assets.comitedebioetica.es/files/noticias/Nota\%20de\%20Prensa\%20-

\%20Informe\%20CBE\%20Seguridad\%20Paciente.pdf

- DATOS RTVE, "Mapa del coronavirus en el mundo: casos, muertes y los últimos datos de su evolución”, DatosRTVE, 2021, disponible en https://www.rtve.es/noticias/20210522/mapa-mundial-delcoronavirus/1998143.shtml\#situacion-mundo

- DAUGHERTY BIDDISON, L., BERKOWITZ, K. A., COURTNEY, B., DICHTER, J. R., CHRISTIAN, M. D., POWELL, T., "Care of the Critically Ill and Injured During Pandemics and Disasters: CHEST Consensus Statement”, CHEST journal, Vol. 146, Núm. 4, 2014, pp. 145-155. https://doi.org/10.1378/chest.14-0742

- DEFENSOR DEL PUEBLO, “Actuaciones ante la pandemia de covid-19”, 2020, disponible en https://www.defensordelpueblo.es/wp-content/uploads/2020/12/Documento_COVID19.pdf

- FAGGIONI, M.P., GONZÁLEZ-MELADO, F.J., DI PIETRO, M.L., "National health system cuts and triage decisions during the COVID-19 pandemic in Italy and Spain: ethical implications.", $J$ Med Ethics, Vol 47, 2021, p. 300-307, disponible en https://jme.bmj.com/content/medethics/47/5/300.full.pdf

- GILLON, R. “Ética médica: cuatro principios más atención al alcance”, BMJ, Vol. 309, 1994, p. 184, disponible en https://www.bmj.com/content/309/6948/184.full

- GOBIERNO DE ESPAÑA, "Estrategia de vacunación COVID-19", disponible en https://www.vacunacovid.gob.es/

- GRUPO DE TRABAJO DE BIOÉTICA DE LA SEMICYUC, "Comunicado de la junta directiva de la Sociedad Española de Medicina Intensiva, Crítica y Unidades Coronarias (SEMICYUC) sobre el informe del Comité de bioética de España sobre los aspectos bioéticos de la priorización de recursos sanitarios en el contexto de la crisis del coronavirus.", semicyuc.org, 1 de abril de 2020, disponible en https://semicyuc.org/wpcontent/uploads/2020/04/Comunicado-SEMICYUC-Bioe\%CC\%81tica.pdf

- GRUPO DE TRABAJO DE BIOÉTICA DE LA SEMICYUC, "Recomendaciones éticas para la toma de decisiones en la situación excepcional de crisis por pandemia covid-19 en las unidades de cuidados intensivos.", semicyuc.org, 19 de marzo de 2020, disponible en https://semicyuc.org/wp-content/uploads/2020/03/\%C3\%89tica_SEMICYUC-COVID19.pdf

- GRUPO DE TRABAJO TÉCNICO DE VACUNACIÓN COVID-19 DE LA PONENCIA DE PROGRAMA Y REGISTRO DE VACUNACIÓN, "Estrategia de vacunación frente a COVID19 en España", Consejo interterritorial sistema nacional de salud, Actualización 3, 9 de febrero de 2021, en https://www.mscbs.gob.es/profesionales/saludPublica/prevPromocion/vacunaciones/covid1 9/docs/COVID-19_Actualizacion3_EstrategiaVacunacion.pdf 
- HERREROS, B., GELLA, P., REAL DE ASUA, D., "Triage during the COVID-19 epidemic in Spain: better and worse ethical arguments", Journal of Medical Ethics, Vol. 46, 2020, pp. 455-458. http://dx.doi.org/10.1136/medethics-2020-106352

- LISA ROSENBAUM, M.D., "Facing Covid-19 in Italy - Ethics, Logistics, and Therapeutics on the Epidemic's Front Line", The new England journal of medicine, 14 de mayo de 2020, disponible en https://www.nejm.org/doi/full/10.1056/nejmp2005492

- MINISTERIO DE SANDIDAD DE ESPAÑA, página web oficial disponible en https://www.mscbs.gob.es/

- MINISTERIO DE SANIDAD DE ESPAÑA, "Informe del Ministerio de Sanidad sobre los aspectos éticos en situaciones de pandemia: El SARS-CoV-2", mscbs.gob.es, 3 de abril de 2020 , disponible

en https://www.mscbs.gob.es/profesionales/saludPublica/ccayes/alertasActual/nCov/document os/AspectosEticos_en_situaciones_de_pandemia.pdf

- MONTALVO JÄÄSKELÄINEN, F., BELLVER CAPELLA, V., "Una crisis bioética dentro de la crisis sanitaria provocada por la covid-19: una reflexión sobre la priorización de pacientes en tiempos de pandemia.", Derecho y Salud, Vol. 30, 2020, disponible en https://www.ajs.es/sites/default/files/2020-07/vol30 Extra 02 05 Estudio.pdf

- ORFALI, K., "What Triage Issues Reveal: Ethics in the COVID-19 Pandemic in Italy and France", Bioethical Inquiry, Vol 17, 2020, pp. 675-679. https://doi.org/10.1007/s11673-020$10059-\mathrm{y}$

- REAL DE ASÚA, D., GALVÁN, J. M., IGLESIAS, J., FERNÁNDEZ, J., (2020). “Criterios de triaje para reanimación cardiopulmonar y soporte vital avanzado durante la epidemia COVID-19", Medicina Clínica, Vol. 155, Núm. 5, 2020, pp. 215-219. https://doi.org/10.1016/j.medcli.2020.04.009

- ROBERTS, M. J., REICH, M. R., "Ethical analysis in public health", The Lancet, Vol. 359, Núm. 9311, 2002, pp. 1055-1059. https://doi.org/10.1016/S0140-6736(02)08097-2

- SAVUlESCU, J., PERSSON, I., WILKINSON, D., "Utilitarismo y pandemia", Bioética, Vol. 34, 2020, pp. 620 - 632. https://doi.org/10.1111/bioe.12771

- SOCIEDADES MEDICO-CIENTÍFICAS, "Comunicado conjunto sobre asistencia a pacientes COVID-19", semicyuc.org, 19 de junio de 2020, disponible en https://semicyuc.org/wp-content/uploads/2020/06/Comunicado-conjunto-10-SS.CC.-19-dejunio-de-2020.pdf

- TAYLOR, R.M., "Ethical principles and concepts in medicine", Handb Clin Neurol., Vol 118, 2013, pp. 1-9. https://doi.org/10.1016/B978-0-444-53501-6.00001-9

- VALLE, R., "La protección de los derechos de las personas con discapacidad en situaciones de crisis: la emergencia sanitaria del COVID-19 en España", Revista Española de Discapacidad, Vol. 8, Núm. 2, 2020, pp. 85-106. https://doi.org/10.5569/2340-5104.08.02.04

- WIBAWA, T., "COVID-19 vaccine research and development: ethical issues", Trop Med Int Health, Vol 26, Num 1, 2021, pp. 14-19. https://dx.doi.org/10.1111\%2Ftmi.13503 